\title{
Hepatoprotective activity of methanolic shoot extract of Bambusa bambos against carbon tetrachloride induce acute liver toxicity in Wistar rats
}

\author{
A. A. Shetti Suman Patil, H Joy Hoskeri, P Rajeev, Bhushan Kulkarni, Geetanjali R Kamble, Gurusiddhesh B Hiremath, \\ Vishal Kalebar, S V Hiremath*
}

Department of biotechnology and Microbiology, P. C. Jabin College, Hubballi, India.

\begin{tabular}{l}
\hline ARTICLE INFO \\
\hline Article history: \\
Received on: June 14, 2017 \\
Accepted on: November 13, 2017 \\
Available online: May 22, 2018 \\
\hline Key words: \\
Bambusa bambos, \\
Hepatoprotective, \\
Methanolic extract, \\
Carbon tetrachloride.
\end{tabular}

\section{INTRODUCTION}

Liver plays an important function of processing and destruction of toxic substance which often enters the body. The liver is exposed to many xenobiotics and therapeutic agents. These substances are processed by hepatic drug metabolism enzymes by releasing polar functional groups onto a drug molecule, for example, cytochrome P450 (CYP) enzyme system. CYP belongs to isozymes family which is responsible for the oxidation of organic substance [1]. Various pharmaceutical industries are looking for liver dysfunction and injuries treatment drugs. There are no specific synthetic drugs to treat the liver injury; due to this, they may cause further damages to the liver.

In India, tribal's are using herbal drugs for the treatment of the liver injuries for a long time. Over $80 \%$ of the Indians as well as world population show faith on the use of traditional medicine based on plant materials [2]. These ancient traditional and natural healthcare practices as well as Ayurveda, Siddha, and Unani originated from

\section{*Corresponding Author:}

Dr. S V Hiremath, Department of Biotechnology and Microbiology, P. C. Jabin College, Hubballi, Karnataka, India. Phone: +91-9480181347.

Email: shivaprakashvhiremath@gmail.com time immemorial and urbanized gradually, to a large extent, without referring any modern scientific principles but only by based on practical experiences [3]. Hepatoprotective plants contain various chemical contents such as phenols, flavonoids, monoterpenes, lignans, glycosides, carotenoids, coumarins, essential oil, alkaloids, organic acids, lipids, and xanthenes. These plants have capacity to speed up the regeneration of liver cells and heal the liver injuries. Many scientists have tested a large number of plants for their active component having the curative property against drug-induced hepatotoxicity model such as Licorice, Solanum xanthocarpum, and Melothria heterophylla [4,5].

Bambusa bambos is well known by its common name Bamboo, Bans, etc., in India. Bamboo is normally distributed throughout the moist region of India. For their growth, some of the species need warm climate, productive soil with rich in water, and some species grow insensibly cold weather. Since ancient time Bamboo has played an important role in human civilization. Apart from all these applications, Bamboo is also known for its medicinal properties. Leaves, roots, shoots, grains, and gums of bamboo are said to be remedy for asthma, cirrhosis, and tumors and have antioxidant as well as antimicrobial properties [6,7]. In many countries, bamboo shoots are consumed as a food, especially young shoots. B. bambos is one of those 200 bamboo species which are edible. The young shoot of B. bambos is used as a food by rural people of Western Ghats in India. These 
are pinkish brown in color and harvested after growing at particular height. Fresh bamboo shoots are appetizing with high fiber content and known to be healthy. It has been reported that $B$. bambos young shoots content various chemical components such as cholin, betain, urease, cyanogenetic glucosides, oxalic acid, and benzoic acid. The leaves of $B$. bambos have been accounted for its antiulcer, antifertility, anti-inflammatory, and antioxidant activity. There are no reports on hepatoprotective activity of the bamboo shoots [8]. Therefore, the present investigation was undertaken to study hepatoprotective activity of $B$. bambos shoot against $\mathrm{CCl}_{4}$-induced liver injury in Wistar rats.

\section{MATERIALS AND METHODS}

\subsection{Collection of Plants}

Bamboo shoots were collected from Yellapur forest area, Uttar Kannada district, Karnataka. Bamboo shoots were authenticated at Department of Botany, Karnataka University, Dharwad. The shoot was dried under shade, powdered mechanically, and stored in air-tight container.

\subsection{Preparation of Methanolic Extract}

B. bambos young shoots were air dried at room temperature and powdered. The powdered shoot is then extracted using methanol in Soxhlet apparatus for $72 \mathrm{~h}$ at the temperature of $40^{\circ} \mathrm{C}$. The extracts were filtered and then evaporated under reduced pressure at $40^{\circ} \mathrm{C}$ to form solid dark brown mass. Collected methanolic extract was semisolid in nature and dark brown in color.

\subsection{Animal}

Female Wister rats of 3-month-old weighing between 250 and $350 \mathrm{~g}$, respectively, were acquired from the S.D.M. Medical College Dharwad, North Karnataka, India. They were housed in polypropylene cages and maintained under standard laboratory environmental conditions; temperature $25^{\circ} \mathrm{C} \pm 2^{\circ} \mathrm{C}, 12 \mathrm{~h}$ light: $12 \mathrm{~h}$ dark cycle and $55 \% \pm 10 \%$ relative humidity with free access to standard pellets and water, ad libitum.

\subsection{Experimental Design}

Wistar rats were divided into six groups as follows, containing five rats in each group. Group I served as normal control with oral administration of olive oil after every $24 \mathrm{~h}$ for 16 days. Groups IIVI were treated with CCl4 mixed with olive oil in ratio of 1:1 at a dose of $1.0 \mathrm{~mL} / \mathrm{kg}$ intraperitoneally every $72 \mathrm{~h}$ for 16 days. Group II animals were maintained as $\mathrm{CCl} 4$ intoxicated control without any drug treatment. Group III was administered silymarin at a dose of $50 \mathrm{mg} / \mathrm{kg}$ of body weight, and Groups VI and V received methanolic bamboo shoot extract 200 and $400 \mathrm{mg} / \mathrm{kg}$ body weight in $0.5 \mathrm{~mL}$ of olive oil orally once daily for 16 days, respectively, in addition to $\mathrm{CCl} 4$ every $72 \mathrm{~h}$ as mentioned above.

\subsection{Biochemical Assay}

Rats were sacrificed on $17^{\text {th }}$ day and blood was collected in the plane tube for aspartate amino transaminase (AST), alanine amino transaminase (ALT), alkaline phosphatase (ALP), and total bilirubin estimation. The blood samples were centrifuged at $5000 \mathrm{rpm}$ for $3 \mathrm{~min}$ at room temperature. The separated blood serums were collected in fresh tube and proceed for further test. Liver marker enzymes such as AST, ALT, and ALP were estimated.

\section{RESULTS}

\subsection{Methanol Extraction of Bamboo Shoot}

Methanol was used for the extraction of phytochemicals from B. bambos shoot through Soxhlet apparatus for $72 \mathrm{~h}$ at the temperature of $40^{\circ} \mathrm{C}-50^{\circ} \mathrm{C}$. Collected methanolic extract $(7.3 \mathrm{~g})$ was semisolid in nature and dark brown in color.

\subsection{Analysis of Serum Biochemical Parameters}

The levels of serum AST, ALT Graph 1, ALP Graph 2, and total bilirubin Graph 3 were considered as marker for hepatotoxicity induced by $\mathrm{CCl}_{4}$.

\subsection{Estimation of AST}

The level of AST elevation in Group II showed more as compared to Group I. In Groups IV and V showed a decreased level of AST compared to Group II. However, Group V has very lower AST level than Group IV which is almost close to Group III [Graph 4].

\subsection{Estimation of ALT}

The level of ALT elevation in Group II showed more as compared to Group I. In Groups IV and V showed a decreased level of ALT compared to Group II. However, Group V has very low ALT level than Group IV which is almost close to Group III [Graph 1].

\subsection{Estimation of ALP}

The level of ALP elevation in Group II showed more as compared to Group I. In Groups IV and V showed a decreased level of ALP

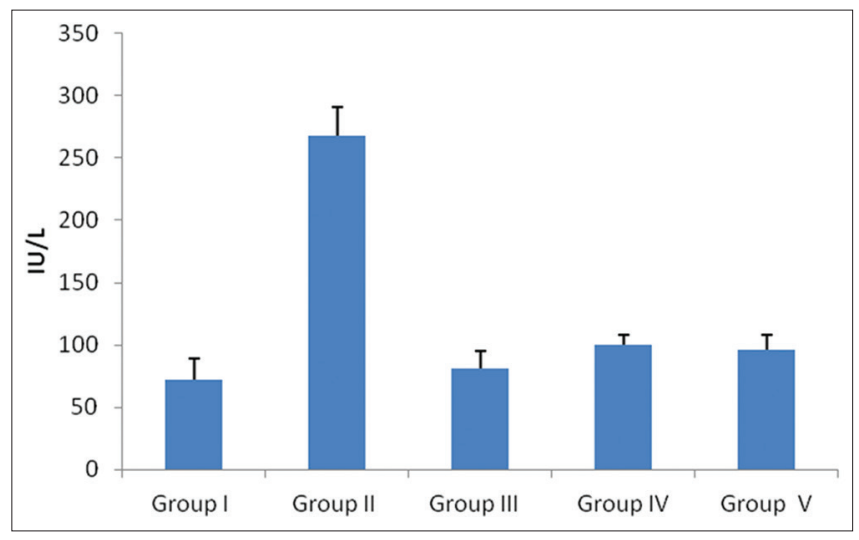

Graph 1: Effects of methanolic shoot extract of Bambusa bambos on serum alanine amino transaminase in carbon tetrachloride-treated Wister rats.

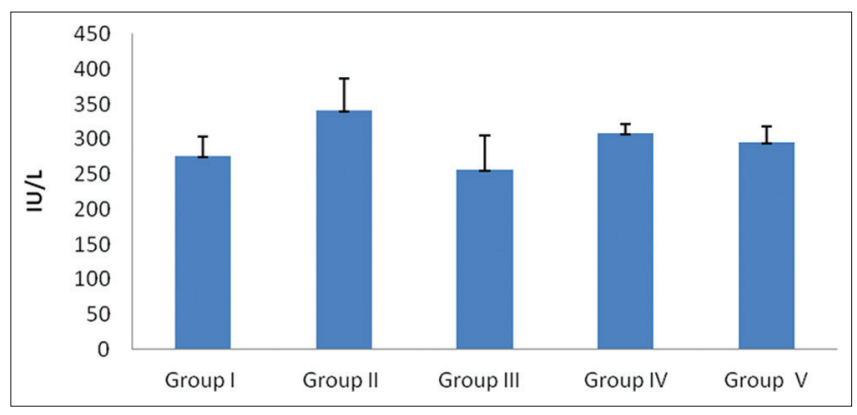

Graph 2: Effects of methanolic shoot extract of Bambusa bambos on serum alkaline phosphatase in carbon tetrachloride-treated Wister rats. 


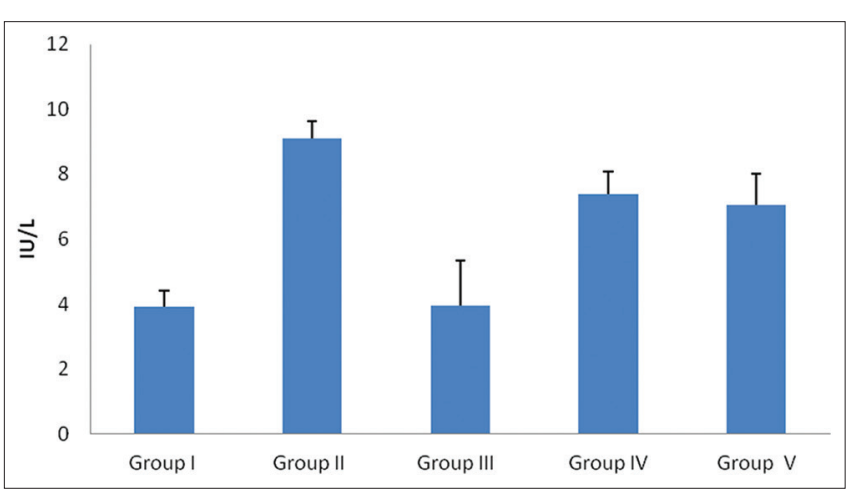

Graph 3: Effect of methanolic shoot extract of Bambusa bambos on total bilirubin in carbon tetrachloride-treated Wister rats.

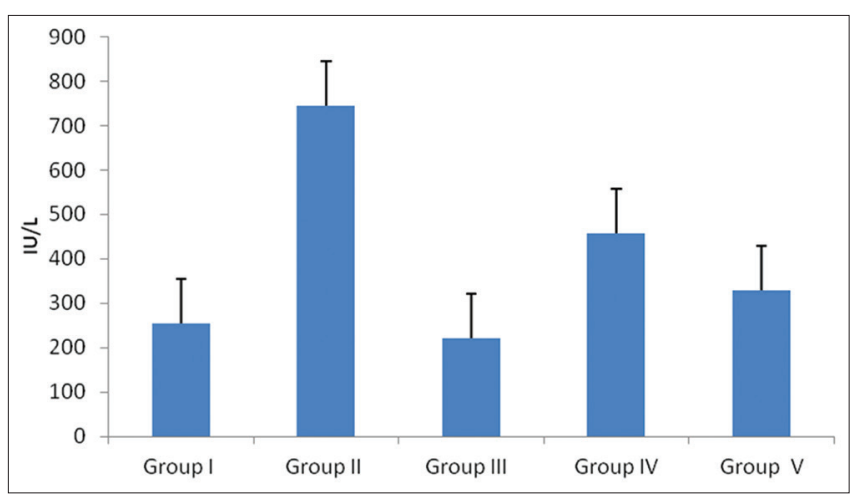

Graph 4: Effects of methanolic shoot extract of Bambusa bambos on serum aspartate amino transaminase in carbon tetrachloride-treated Wistar rats.

compared to Group II. However, Group V has very low ALP level than Group IV which is almost close to Group III [Graph 2].

\subsection{Estimation of Total Bilirubin}

The level of total bilirubin in Group II showed more as compared to Group I. In Groups IV and V showed a decreased level of total bilirubin compared to Group II. However, Group V has very low total bilirubin level than Group IV which is almost close to Group III [Graph 3].

\section{DISCUSSION}

Methanol can dissolve more polar compounds from the plants then ethanol. Many studies have investigated that methanol and ethanol can dissolve polar compounds such as amino acid, sugar, glycoside compounds, phenolic compounds with low and medium molecular weights and medium polarity $[9,10]$, anthocyanin, terpenoid, aglycon flavonoid, saponin, tannin, phenone, totarol, quacinoid, xantoxilin, lactone, flavone, and polyphenol [11]. Hence, in the present investigation, carbon tetrachloride is attested for the production free radicals, which influence the cellular permeability of hepatocytes leading to serum enzyme elevation in blood. Serum marker enzymes and total bilirubin were analyzed and compared with control and experimental animals. In Group II (negative control), treated with $\mathrm{CCl}_{4}$, showed significantly increase $(P<0.05)$ level of enzymes when compared with Group I (normal control). Groups IV and V, treated with methanolic shoot extract of $B$. bambos, showed significantly decline levels of the enzyme $(P<0.001)$ when compared to negative control, but not as low as Group III (positive control) treated with silymarin.
Methanolic shoot extract of $B$. bambos reveals a hepatoprotective effect, showing significant decrease in transaminases, AST and ALT, concentrations in the liver of rats with $\mathrm{CCl}_{4}$-induced hepatotoxicity [Graphs 1,2,4]. During liver injury, AST and ALT are elevated from the hepatocyte into bloodstream that is used as marker for liver damage. In Group II (negative control), found rise in transaminase concentration as compared to Group I (normal control), this indicates liver injury caused by $\mathrm{CCl}_{4}$ in Group II. In general, $\mathrm{CCl}_{4}$ generates a trichloromethyl free radical by cleaving carbon-chlorine bond that reacts rapidly with oxygen producing a trichloromethyl peroxy radical that may induce hepatotoxicity [12].

In positive control treated with $\mathrm{CCl}_{4}$ along with silymarin has shown rapidly decreased the level of AST and ALT as compared to negative control, which indicates hepatoprotective effect, hence, used as standard drug. Silymarin forms a complex that obstructs the entry of toxins into the interior of liver cells. Silymarin metabolism also activates the RNA biosynthesis of ribosomes to induce protein formation by stimulating hepatic cells $[13,14]$.

In groups treated with $\mathrm{CCl}_{4}$ along with low dosage $(200 \mathrm{mg} / \mathrm{kg}$ body weight [bw]) and high dosage (400 $\mathrm{mg} / \mathrm{kg} \mathrm{bw})$ of $B$. bambos for 16 days exhibiting reduction in AST and ALT concentration when compared with negative control. This reveals the ability of $B$. bambos to protect the hepatocyte from the $\mathrm{CCl}_{4}$ exposure. The group treated with high dosage of extract has shown considerably low concentration of serum transaminases than lower dosage group which is almost similar to silymarin group. ALP and total bilirubin [Graphs 1 and 3] were also found to be decrease in experimental extract-treated groups when compared with negative group [15].

The comparison of the hepatoprotective ability of B. bambos shoot was similar to with other plants such as Musa sapientum Linn., Shekwasha (Citrus depressa), wild ginseng cambial meristematic cells, and S. xanthocarpum [16]. Among these plants, most effective was found to be Shekwasha (C. depressa) and S. xanthocarpum. There was reduction in AST, ALT, ALP, and total bilirubin in $\mathrm{CCl}_{4}$-induced hepatotoxicity in rats when treated with $\mathrm{B}$. bambos that was comparible to Shekwasha and S. xanthocarpum. Shekwasha fruit has the ability to suppress D-galactosamine and protect the liver in D-galactosamine-induced liver injury due to the presence of polymethoxy flavonoids such as citromitin, tangeretin, and specially nobiletin. Whereas, the phytochemical screening of S. xanthocarpum reported the presence of flavonoids, steroidal alkaloids, flavonoids, triterpenes, apigenins glycosides, and quercitrin that are involved in hepatoprotection activity [16,17]. In this study, B. bambos shows the same characteristic in of suppression $\mathrm{CCl}_{4}$ - toxicity that may indicate the presence of flavonoids, steroidal alkaloids, etc., which are the major constituents induce the hepatoprotection that are comparable with the control and standard hepatoprotectant (Silymarin).

\section{CONCLUSION}

In the present study, methanolic shoot extract of $B$. bambos was analyzed for its hepatoprotective activity against model hepatotoxicant $\mathrm{CCl}_{4}$ in Wistar rats by studying the activity of AST, ALT, ALP, and total bilirubin. The extract showed hepatoprotective activity which was dose-dependent and maximum beneficial effect was observed at a dose of $400 \mathrm{mg} / \mathrm{kg}$. The results were comparable with that of standard drug, silymarin used in the study. The hepatoprotective action is perhaps related to its potent antioxidant activity. Further, 
investigations are required to characterize the active hepatoprotective agent and mechanism of action.

\section{REFERENCES}

1. Sun F, Hamagawa E, Tsutsui C, Ono Y, Ogiri Y, Kojo S, et al. Evaluation of oxidative stress during apoptosis and necrosis caused by carbon tetrachloride in rat liver. Biochim Biophys Acta 2001;1535:186-91.

2. Park EJ, Jeon CH, Ko G, Kim J, Sohn DH. Protective effect of curcumin in rat liver injury induced by carbon tetrachloride. J Pharm Pharmacol 2000;52:437-40.

3. Reddy GV, Kumar RV, Rama V, Reddy MK, Reddy YN. Preliminary hepatoprotective activity of medicinal plant extracts against carbon tetrachloride induced hepatotoxicity in albino rats. Int J Rec Sci Res 2015;6:4946-51.

4. Slinkard K, Singleto VL. Total phenol analyses automation and comparison with manual methods. Am J Enol Viticult 1977;28:49-55.

5. Khare CP. Indian Medicinal Plants. An Illustrated Dictionary. New Delhi, India: Springer Publication; 2007.

6. Rathod JD, Pathak NL, Patel RG, Jivani NP, Bhatt NM. Phytopharmacological properties of Bambusa arundinacea as a potential medicinal tree: An overview. J Appl Pharm Sci 2011;1:27-31.

7. Mamat SS, Kamarolzaman MF, Yahya F, Mahmood ND, Shahril MS, Jakius KF, et al. Methanol extract of Melastoma malabathricum leaves exerted antioxidant and liver protective activity in rats. BMC Complement Altern Med 2013;13:326.

8. Yuan L, Gu X, Yin Z, Kang W. Antioxidantactivities in vitro and hepatoprotective effects of Nelumbo nucifera leaves in vivo complement altern med. Afr J Tradit 2014;11:85-91.

9. Akah PA, Odo CI. Hepatoprotective effect of the solvent fractions of the stem of Hoslundia opposita Vahl (Lamiaceae) against carbon tetrachloride- and paracetamol-induced liver damage in rats. Int $\mathrm{J}$ Green Pharm 2010;4:54-8.
10. Huo HZ, Wang B, Liang YK, Bao YY, Gu Y. Hepatoprotective and antioxidant effects of licorice extract against $\mathrm{CCl}_{4}$-induced oxidative damage in rats. Int J Mol Sci 2011;12:6529-43.

11. Suruchi S, Thomas MB, Singh SP, Bhowmik D. Plants used in hepatoprotective remedies in traditional Indian medicine. Ind J Res Pharm Biotechnol 2013;1:58-63.

12. Agarwal AK, Mehendale JK. Potentiation of carbon tetrachloride hepatotoxicity and lethality by chlordecone in female rats. Toxicology 1983;26:231-42.

13. Gupta RK, Hussain T, Panigrahi G, Das A, Singh GN, Sweety K, et al. Hepatoprotective effect of Solanum xanthocarpum fruit extract against $\mathrm{CCl} 4$ induced acute liver toxicity in experimental animals. Asian Pac J Trop Med 2011;4:964-8.

14. Okokon JE, Simeon JO, Umoh EE. Hepatoprotective activity of the extract of Homalium letestui stem against paracetamol-induced liver injury. Avicenna J Phytomed 2017;7:27-36.

15. Dikshit P, Tyagi MK, Shukla K, Sharma S, Gambhir JK, Shukla R, et al. Hepatoprotective effect of stem of Musa sapientum linn in rats intoxicated with carbon tetrachloride. Ann Hepatol 2011;10:333-9.

16. Putri H, Nagadi S, Larasati YA, Wulandari N, Hermawan A, Nugroho AE, et al. Cardioprotective and hepatoprotective effects of citrus hystrix peels extract on rats model. Asian Pac J Trop Biomed 2013;3:371-5.

17. Akbartabar Toori M, Joodi B, Sadeghi H, Sadeghi H, Jafari M, Talebianpoor MS, et al. Hepatoprotective activity of aerial parts of Otostegia persica against carbon tetrachloride-induced liver damage in rats. Avicenna J Phytomed 2015;5:238-46.

\section{How to cite this article:}

Patil S, Shetti A, Hoskeri HJ, Rajeev P, Kulkarni B, Kamble GR,

Hiremath GB, Kalebar V, Hiremath SV. Hepatoprotective activity

of methanolic shoot extract of Bambusa bambos against carbon

tetrachloride induce acute liver toxicity in Wistar rats. J App Biol Biotech.

2018;6(04):37-40. DOI: 10.7324/JABB.2018.60407 